\title{
Determinants of Adherence to Diabetes Screening in Iranian Adults With a Positive Family History of Diabetes
}

\author{
Narges Malih ${ }^{1,2}$, Mohammad-Reza Sohrabi ${ }^{1,2}$, Alireza Abadi ${ }^{1,2}$, Shahnam Arshi' \\ ${ }^{1}$ Social Determinants of Health Research Center, School of Medicine, Shahid Beheshti University of Medical Sciences, Tehran, Iran; ${ }^{2}$ Department of \\ Community Medicine, School of Medicine, Shahid Beheshti University of Medical Sciences, Tehran, Iran
}

Objectives: Insufficient evidence exists regarding factors that affect screening adherence among people with a family history of diabetes, who comprise roughly half of all patients with diabetes. Therefore, we aimed to identify the determinants of diabetes screening adherence in adults with a family history of diabetes who had not yet been diagnosed with diabetes.

Methods: This cross-sectional study was conducted at selected urban primary healthcare facilities in Tehran, Iran. The study population was clinically non-diabetic adults above 20 years of age with a family history of diabetes in at least 1 first-degree relative. All eligible people identified on randomly-selected days of the month were invited to join the study.

Results: Among 408 participants, 128 (31.4\%) had received a fasting blood glucose check during the last year. Using binary logistic regression, the independent predictors of screening adherence were knowledge of adverse effects of diabetes such as sexual disorders (odds ratio $[\mathrm{OR}], 3.05)$ and renal failure $(\mathrm{OR}, 2.73)$, the impact of family members' advice on receiving diabetes screening (OR, 2.03), recommendation from a healthcare provider to have a fasting blood glucose check (OR, 2.61), and intention to have a fasting blood glucose check within the next 6 months (OR, 2.85). Other variables that predicted screening adherence were age (OR, 1.05), job (being a housekeeper; OR, 3.39), and having a college degree (OR, 3.55).

Conclusions: Knowledge of the adverse effects of diabetes, physicians' and healthcare providers' advice about the benefits of early disease detection, and family members' advice were independent predictors of screening adherence.

Key words: Blood glucose, Diabetes mellitus, Intention, Medical history taking, Mass screening

\section{INTRODUCTION}

Diabetes is a common chronic disease that affects people worldwide. Approximately 415 million people were diagnosed

Received: October 10, 2020 Accepted: March 14, 2021

Corresponding author: Mohammad-Reza Sohrabi Department of Community Medicine, School of Medicine, Shahid Beheshti University of Medical Sciences, P.O. Box 193954719, Tehran, Iran

E-mail:m.sohrabi@sbmu.ac.ir

This is an Open Access article distributed under the terms of the Creative Commons Attribution Non-Commercial License (https://creativecommons.org/licenses/by$\mathrm{nc} / 4.0 /$ ) which permits unrestricted non-commercial use, distribution, and reproduction in any medium, provided the original work is properly cited. with diabetes in 2015, and this figure is predicted to reach 642 million by 2040 [1]. Studies have shown that diabetes caused 1.5 million deaths and 89 million disability-adjusted life-years in 2012 [2]. It is estimated that $45.8 \%$ or 174.8 million of all adult cases of diabetes have remained undiagnosed. Every year, approximately $4 \%$ of people with previously normal blood glucose levels are diagnosed with prediabetes [3]. Statistics have shown that more than $80 \%$ of cases of undiagnosed diabetes are in countries with low and middle income levels [4].

Approximately half of patients with diabetes have a positive family history, which could be identified as an important predictor of elevated blood glucose levels [5]. Since half of people with diabetes remain undiagnosed, people with a positive 
family history of diabetes are a particularly promising group for identifying these cases [6-11]. Although this effect is well known, most studies have focused on participants' views regarding diabetes screening and have not explored the factors associated with participants' adherence to diabetes screening programs [12-16]. Thus, there is insufficient evidence on factors that affect the screening adherence of people who have at least 1 family member diagnosed with diabetes [12]. Furthermore, studies have shown that a high level of knowledge of diabetes was not associated with changes in attitudes and practices for diabetes prevention $[17,18]$.

This study was designed to identify the determinants of screening for diabetes among adults with a family history of diabetes, as a high-risk population, who had not yet been diagnosed with diabetes.

\section{METHODS}

This cross-sectional study was conducted at selected urban primary healthcare facilities in Tehran, the capital city of Iran. All the healthcare facilities had diabetes control and prevention units that provided care as part of the Diabetes Prevention and Control Program (DPCP), which recommends that diabetes screening should be considered in adults with a family history of diabetes in a first-degree family member (parents, siblings, or offspring) $[19,20]$.

The study population was clinically non-diabetic adults aged 20 or over with a family history of diabetes in at least 1 first-degree relative (parent, sibling, or child) who presented for non-diabetes-related care at a selected urban primary care facility. All eligible patients on randomly-selected days of the month were invited to join the study. Participants were interviewed by a single researcher to prevent interviewer bias. A free blood glucose test was done with a glucometer as encouragement for participants. Females with a history of pregnancy during the past year were excluded from the study because of routine check-ups for gestational diabetes [21,22].

The sample size was calculated considering a type 1 error of $5 \%$, a level of accuracy of $0.05,95 \%$ confidence interval $(\mathrm{Cl})$, and a $50 \%$ prevalence of having had a fasting blood sugar test. This calculation yielded a sample size of 384 .

The data collecting form was a self-reported questionnaire that was developed by the researchers for measuring screening behavior. The face, construct, and content validity of the instrument was evaluated and confirmed by faculty members of Shahid Beheshti University of Medical Sciences with expertise in endocrinology, community medicine, and epidemiology. Considering the dichotomous nature of the variables for each item regarding knowledge of symptoms and adverse effects of diabetes, the Kuder-Richardson coefficient was used to assess the reliability of the questions in the knowledge section (Kuder-Richardson coefficient $=0.83$ ). The dependent variable (a history of having received a diabetes screening test) was measured according to whether or not participants had received at least 1 fasting blood glucose test. Participants were also asked to provide information on socio-demographic characteristics, including age (year), sex, job, education, marital status, and health insurance coverage.

Participants' weight and height were measured, and their body mass index (BMI) was calculated as weight in kilograms divided by height in meters squared. BMI was categorized according to the National Institute of Health guidelines as follows: optimal or underweight $\left(<25.0 \mathrm{~kg} / \mathrm{m}^{2}\right)$, overweight $\left(25.0-29.9 \mathrm{~kg} / \mathrm{m}^{2}\right)$, and obese $\left(\geq 30.0 \mathrm{~kg} / \mathrm{m}^{2}\right)$.

Considering the Health Belief Model and the theory of planned behavior [23,24], as well as the possible effect of basic knowledge about diabetes on screening adherence, the questions regarding various aspects of diabetes screening adherence of the participants are illustrated in Supplemental Material 1.

\section{Statistical Analysis}

Since a trained investigator completed the questionnaires, the level of missing data was relatively low. SPSS version 14 (SPSS Inc., Chicago, IL, USA) was used for the statistical analysis. The chi-square test, Fisher exact test, and Mantel-Haenszel chi-square test were used to investigate associations between study variables and screening adherence. The independent sample $t$-test was used to determine the statistical significance of associations between quantitative variables and screening adherence. Since the outcome variable (history of diabetes screening by a fasting blood glucose test; yes/no) was dichotomous, binary logistic regression (stepwise forward entry) was performed for modeling. The level of statistical significance was considered as $p$-value $<0.05$.

\section{Ethics Statement}

This study is extracted from community medicine residency thesis and the study design has been approved by Ethical Committee of Shahid Beheshti University of Medical Sciences (No. p22815). Participants entered the study after providing 
informed consent. The questionnaires were anonymous and all the data were kept confidential. The study was done in ac-

Table 1. Socio-demographic variables by screening status

\begin{tabular}{|c|c|c|c|c|c|}
\hline \multirow{2}{*}{ Variables } & \multicolumn{3}{|c|}{ Screening for diabetes at least once } & \multirow{2}{*}{$\chi^{2}$} & \multirow{2}{*}{$p$-value } \\
\hline & No & Yes & Total & & \\
\hline \multicolumn{4}{|l|}{ Sex } & 9.58 & 0.002 \\
\hline Female & $64(68.1)$ & $260(82.8)$ & $324(79.4)$ & & \\
\hline Male & $30(31.9)$ & $54(17.2)$ & $84(20.6)$ & & \\
\hline \multicolumn{4}{|l|}{ Age (y) } & 3.61 & $0.057^{1}$ \\
\hline$<45$ & $82(87.2)$ & $239(76.1)$ & $321(78.7)$ & & \\
\hline$\geq 45$ & $12(12.8)$ & $75(23.9)$ & $87(21.3)$ & & \\
\hline \multicolumn{4}{|l|}{ Marital status } & 8.55 & 0.002 \\
\hline Never married & $12(12.9)$ & $13(4.1)$ & $25(6.1)$ & & \\
\hline Married & $81(87.1)$ & 301 (95.9) & $382(93.9)$ & & \\
\hline \multicolumn{4}{|l|}{ College education } & 3.89 & 0.480 \\
\hline Yes & $28(29.8)$ & $129(41.1)$ & $157(38.5)$ & & \\
\hline No & 66 (70.2) & $185(58.9)$ & $251(61.5)$ & & \\
\hline \multicolumn{4}{|l|}{ Currently working } & 1.03 & $0.300^{1}$ \\
\hline No & $43(45.7)$ & $192(61.1)$ & $235(57.6)$ & & \\
\hline Yes & $51(54.3)$ & $122(38.9)$ & $173(42.4)$ & & \\
\hline \multicolumn{4}{|l|}{ Health insurance } & 6.75 & 0.009 \\
\hline Yes & $81(86.2)$ & $296(94.3)$ & $377(92.4)$ & & \\
\hline No & $13(13.8)$ & $18(5.7)$ & $31(7.6)$ & & \\
\hline \multicolumn{4}{|c|}{ Father with diabetes } & 0.01 & 0.920 \\
\hline Yes & 39 (41.5) & $132(42)$ & $171(41.9)$ & & \\
\hline No & $55(58.5)$ & $182(58)$ & $237(58.1)$ & & \\
\hline \multicolumn{4}{|c|}{ Mother with diabetes } & 0.11 & 0.730 \\
\hline Yes & $56(59.6)$ & $181(57.6)$ & $237(58.1)$ & & \\
\hline No & $38(40.4)$ & $133(42.4)$ & 171 (41.9) & & \\
\hline \multicolumn{4}{|c|}{ Brother with diabetes } & 0.16 & 0.680 \\
\hline Yes & $6(6.4)$ & $24(7.6)$ & $30(7.4)$ & & \\
\hline No & $88(93.6)$ & $290(92.4)$ & $378(92.6)$ & & \\
\hline \multicolumn{4}{|c|}{ Sister with diabetes } & 0.50 & 0.470 \\
\hline Yes & $7(7.4)$ & $31(9.9)$ & $38(9.3)$ & & \\
\hline No & 87 (92.6) & $283(90.1)$ & $370(90.7)$ & & \\
\hline \multicolumn{4}{|c|}{ Child with diabetes } & 0.90 & $1.000^{2}$ \\
\hline Yes & $0(0.0)$ & $3(1.0)$ & $3(0.7)$ & & \\
\hline No & $94(100)$ & $311(99.0)$ & 405 (99.3) & & \\
\hline \multicolumn{4}{|l|}{ Hypertension } & 0.12 & 0.720 \\
\hline Yes & $9(9.6)$ & $34(10.8)$ & $43(10.5)$ & & \\
\hline No & $85(90.4)$ & $280(89.2)$ & 365 (89.5) & & \\
\hline \multicolumn{4}{|l|}{ History of GDM } & 4.58 & 0.030 \\
\hline Yes & $2(2.1)$ & $27(8.6)$ & $29(7.1)$ & & \\
\hline No & $92(97.9)$ & $287(91.4)$ & $379(92.9)$ & & \\
\hline
\end{tabular}

Values are presented as number (\%).

GDM, gestational diabetes mellitus.

${ }^{1}$ Mantel-Haenszel chi-square, adjusted for sex.

${ }^{2}$ Fisher exact test. cordance with the Declaration of Helsinki and its later amendments.

\section{RESULTS}

In total, 408 individuals with a positive family history of diabetes participated in the study. Participants' socio-demographic characteristics are illustrated in Table 1. The mean \pm standard deviation age of participants was $37.40 \pm 10.64$ years overall, $37.80 \pm 11.14$ for females, and $35.80 \pm 8.34$ for males $(p=0.09)$. The participants' age ranged from 20 years to 79 years. Among the 408 participants with a family history of diabetes, 314 (76.9\%) had been screened for diabetes at least once; among the screened participants, 128 (31.4\%) had been screened in the year preceding the study. The analysis showed that 260 $(82.8 \%)$ of participants who had been screened were female $(p=0.002)$, and participants who had been screened for diabetes were predominantly under 45 years of age $(n=239 ; 76.1 \%$; $p=0.05)$. Among the people who had been screened, 296 (94.3\%) had health insurance. In females with a history of gestational diabetes mellitus $27(8.6 \%)$ had been screened for dia-

Table 2. Comparison of lifestyle characteristics according to whether participants had received a diabetes screening test

\begin{tabular}{|c|c|c|c|c|c|}
\hline \multirow{2}{*}{ Characteristics } & \multicolumn{3}{|c|}{ Screening for diabetes } & \multirow{2}{*}{$\chi^{2}$} & \multirow{2}{*}{$p$-value } \\
\hline & No & Yes & Total & & \\
\hline \multicolumn{4}{|l|}{ Current smoking } & 0.04 & $0.84^{1}$ \\
\hline Yes & $8(8.5)$ & $15(4.8)$ & $23(5.6)$ & & \\
\hline No & $86(91.5)$ & $299(95.2)$ & $385(94.4)$ & & \\
\hline \multicolumn{4}{|c|}{ Body mass index $\left(\mathrm{kg} / \mathrm{m}^{2}\right)$} & 2.88 & 0.23 \\
\hline$<25.0$ & $36(43.4)$ & $96(33.4)$ & $132(35.7)$ & & \\
\hline 25.0-29.9 & $34(41.0)$ & $133(46.3)$ & $167(45.1)$ & & \\
\hline$\geq 30.0$ & $13(15.7)$ & $58(20.2)$ & $71(19.2)$ & & \\
\hline \multicolumn{4}{|l|}{ Physical activity } & 0.62 & 0.43 \\
\hline Inactive & $62(66.0)$ & $193(61.5)$ & $255(62.5)$ & & \\
\hline Active & $32(34.0)$ & $121(38.5)$ & $153(37.5)$ & & \\
\hline \multicolumn{4}{|c|}{ Fruit and vegetable consumption (servings/d) } & 0.35 & 0.55 \\
\hline$<5$ & $80(85.1)$ & $259(82.5)$ & $399(83.1)$ & & \\
\hline$\geq 5$ & $14(14.9)$ & $55(17.5)$ & $69(16.9)$ & & \\
\hline \multicolumn{4}{|c|}{ Weekly fast food consumption } & 5.54 & $0.01^{1}$ \\
\hline Not at all & $58(61.7)$ & $242(77.1)$ & $300(73.5)$ & & \\
\hline At least once & 36 (38.3) & $72(22.9)$ & $108(26.5)$ & & \\
\hline \multicolumn{4}{|c|}{ Weekly sugar-containing beverage consumption } & 0.01 & $0.92^{1}$ \\
\hline Not at all & $44(46.8)$ & $155(49.4)$ & $199(48.8)$ & & \\
\hline At least once & $50(53.2)$ & $159(50.6)$ & $209(51.2)$ & & \\
\hline
\end{tabular}

Values are presented as number (\%).

${ }^{1}$ Mantel-Haenszel chi-square, adjusted for sex. 
betes at least once (Table 1).

Thirty individuals $(7.4 \%)$ reported having had a hemoglobin A1c test at least once, all of whom had also received at least 1 fasting blood glucose test.

Table 2 presents a comparison of lifestyle factors between screened and unscreened people. A notable finding was that 242 (77.1\%) of the participants who had been screened for diabetes at least once did not consume fast food weekly $(p=0.01)$.

Logistic regression analysis was used to test hypothesized

Table 3. Binary logistic regression analysis (forward stepwise logistic regression) of selected variables and dependent variable (history of diabetes screening at least once)

\begin{tabular}{lcccc}
\hline Predictors & Adjusted & $\boldsymbol{p}$-value & Undajusted & $\boldsymbol{p}$-value \\
\hline Age & $1.05(1.02,1.10)$ & 0.003 & $1.05(1.02,1.08)$ & $<0.001$ \\
College education & & & & \\
No & 1.00 (reference) & & 1.00 (reference) & \\
Yes & $3.55(1.60,7.87)$ & 0.002 & $1.64(1.00,2.69)^{1}$ & 0.050 \\
Occupation & & & & \\
Governmental & 1.00 (reference) & & 1.00 (reference) & \\
Non-governmental & $0.59(0.23,1.52)$ & 0.280 & $0.33(0.16,0.66)$ & 0.002 \\
Housekeeper & $3.39(1.36,8.43)$ & 0.008 & $1.24(0.68,2.28)$ & 0.470 \\
Other & $0.52(0.14,1.87)$ & 0.320 & $0.48(0.17,1.29)$ & 0.140 \\
Weekly fast food consumption & & & \\
Not at all & 1.00 (reference) & & $1.00($ reference) & \\
At least once & $0.52(0.28,0.98)$ & 0.046 & $0.47(0.29,0.78)$ & 0.003 \\
Considering urinalysis as the screening method & & \\
No & 1.00 (reference) & & - & \\
Yes & 0.20 (0.07, 0.54) & 0.001 & - & 0.100
\end{tabular}

Knowledge of the adverse effects of diabetes (renal failure)

No $\quad 1.00$ (reference) $\quad 1.00$ (reference)

Yes $\quad 2.73(1.37,5.46) \quad 0.004 \quad 2.17(1.26,3.74) \quad 0.005$

Knowledge of the adverse effects of diabetes (sexual disorder)

$\begin{array}{lllll}\text { No } & 1.00 \text { (reference) } & 1.00 \text { (reference) } & \\ \text { Yes } & 3.05(1.55,5.99) & 0.001 & 3.70(2.13,6.41) & <0.001\end{array}$

Intention to have a fasting blood glucose check within the next 6 mo

No $\quad 1.00$ (reference) $\quad 1.00$ (reference)

$\begin{array}{lllll}\text { Yes } \quad 2.85(1.31,6.22) & 0.008 & 2.11(1.17,3.81) & 0.010\end{array}$

Impact of family members' advice on having diabetes screening

$\begin{array}{lcrlr}\text { No } & 1.00 \text { (reference) } & - & \\ \text { Yes } & 2.03(1.00,4.13) & 0.049 & - & 0.250 \\ \text { Recommendations by a health care provider to have a fasting } & \\ \text { blood glucose check } & & & \\ \text { No } & 1.00 \text { (reference) } & 1.00 \text { (reference) } & \\ \text { Yes } & 2.61(1.36,4.99) & 0.004 & 2.86(1.69,4.84) & <0.001 \\ \text { Constant } & 0.41^{1} & <0.001 & \end{array}$

Values are presented odds ratio ( $95 \%$ confidence interval).

'Borderline significance. relationships between the dependent variable (adherence to diabetes screening) and selected independent variables. The model predicted $36.4 \%$ of variance in screening adherence. Table 3 shows the results of the logistic regression analysis. Independent predictors of adherence to screening were knowledge of adverse effects of diabetes such as sexual disorders (odds ratio [OR], 3.05; 95\% Cl, 1.55 to 5.99) and renal failure (OR, $2.73 ; 95 \% \mathrm{Cl}, 1.37$ to 5.46$)$, the impact of family members' advice on receiving diabetes screening $(\mathrm{OR}, 2.03 ; 95 \% \mathrm{Cl}, 1.00$ to 4.13), recommendations from a healthcare provider to have a fasting blood glucose check (OR, 2.61; $95 \% \mathrm{Cl}, 1.36$ to 4.99$)$, and intention to have an fasting blood glucose check within the next 6 months (OR, 2.85; 95\% Cl, 1.31 to 6.22). Other variables that predicted screening adherence were age (OR, 1.05; $95 \% \mathrm{Cl}, 1.02$ to 1.10), occupation (being a housekeeper: OR, $3.39 ; 95 \% \mathrm{Cl}, 1.36$ to 8.43 ), and having a college degree (OR, $3.55 ; 95 \% \mathrm{Cl}, 1.60$ to 7.87$)$. Moreover, the odds of diabetes screening adherence increased by $5 \%$ for each year of life.

Perceived susceptibility, perceived severity, perceived barriers, knowledge of symptoms and risk factors for diabetes, and knowing about the DPCP were not identified as significant predictors according to the logistic regression analysis.

\section{DISCUSSION}

The following factors were identified as independent predictors of adherence to diabetes screening: age, education, being a housekeeper, fast food consumption, knowledge of the most appropriate screening method and complications of diabetes, the impact of family members' advice on deciding whether or not to receive a diabetes screening test, recommendations from a healthcare provider to have a fasting blood glucose check, and intention to have a fasting blood glucose check within the next 6 months.

In the present study, $80.2 \%$ of female participants and $64.3 \%$ of male participants had been screened at least once for diabetes. This finding is in accordance with those of Wilson et al. [25], who reported screening adherence rates of $80 \%$ and $66 \%$ in female and male participants, respectively, during a 5 -year period. This study, as well as that of Baptiste-Roberts et al. [15], did not find participants' sex to be a predictor of screening adherence. Nijhof et al. [26] reported a significantly higher number of female in the screened group, and that sex was not a predictor of adherence to diabetes screening. The screening adherence rate in females with diabetes was significantly high- 
er than that in males; although sex was not included in the predictive model, it is important to pay attention to males, who are less interested in screening [27]. The lower rate of screening adherence in male was reported to be due to their fear of developing diabetes and their lower risk perception [28].

In this study, the advice of physicians and healthcare providers for checking fasting blood glucose was an independent predictor of adherence to screening. This finding is similar to that of Chang et al. [29], who reported that the advice of a physician was associated with participants acting to reduce diabetes risks. Another study by Shah and Booth [30] evaluated predictors of attendance at a diabetes education center and identified regular specialist and primary care visits as the strongest predictor of attendance. However, a study by Polubriaginof et al. [31] reported that among the eligible-for-screening cohort, $30.6 \%$ of the participants did not receive diabetes screening based on current recommendations, and that having more than 1 family member affected by diabetes increased the likelihood of screening. Furthermore, in a study in rural health centers in Aklan in the Philippines, healthcare professionals had neutral diabetes-attitude scale scores and they believed that special training was needed for type 2 diabetes [32]. In combination with the results of Edelman et al. [33] who reported that having a primary care provider did not raise or lower the risk for undiagnosed diabetes in screened patients for diabetes, the aforementioned findings could show that healthcare providers' knowledge of the importance of diabetes screening does not guarantee that they provide advice on screening or that patients adhere to screening.

The present study found that a family member's advice had a significant effect on adherence to screening among diabetes-free adults. In a study by Badlishah-Sham et al. [34], Malaysian type 2 diabetes patients agreed that discussions with their children helped them to prevent type 2 diabetes. Health advice from family members can modify the behavior of other family members, but similar studies have not evaluated whether advice is associated with screening adherence $[7,15,16,26,29]$.

The findings of the present study demonstrated that increasing age affected adherence to screening, but in another study, Nijhof et al. [26] reported that this association was not significant; however, it seems that older adults perceive themselves to be at a higher risk of disease, so they pay more attention to screening tests [21]. Baptiste-Roberts et al. [15] reported that older age had a significant association with knowledge of risk factors for diabetes. It is important to detect the disease as early as possible to reduce the probability of complications or to control them at an early stage.

Although the effects of occupation have not been evaluated in prior studies, the findings of the adjusted binary logistic regression model in this study suggested that being a housekeeper increased the likelihood of getting tested by 3.39-fold compared with those employed in a governmental job [15,26, 29]. It is noteworthy that in the unadjusted binary logistic regression model, having a non-governmental job $(\mathrm{OR}, 0.33)$ was an independent predictor of diabetes screening adherence. Furthermore, the findings of bivariate analysis using the Mantel-Haenszel chi-square test, which was adjusted for sex, did not show an effect of occupation on screening adherence. Considering the aforementioned issues, the finding that being a housekeeper was an independent predictor of screening adherence might have been due to possible interactions of other variables in the regression model.

College education had a significant association with adherence to screening, but Nijhof et al. [26] and other researchers $[15,29]$ reported that a high level of education, despite its negative effect on diabetes risk testing, was not determined to be significant.

Having a family history of diabetes was found to cause healthpromoting behavior such as healthy eating [7]. In this study, the consumption of fruit and vegetables was not a predictor of adherence to screening. In the present study, $16.9 \%$ of participants followed the World Health Organization [35] recommendation to consume at least 5 servings of fruit and vegetables per day. Baptiste-Roberts et al. [15] reported that people with a family member with diabetes were more likely to consume 5 or more servings of fruits and vegetables per day than those without a family history of diabetes ( 26.9 vs. $20.4 \%$ ), but in another study, Zlot et al. [27] reported that a family history of diabetes was not a predictor of increased consumption of fruit and vegetables.

Knowledge of the risk factors for diabetes was not identified as a predictor of screening in this study. Omolafe et al. [36] found that healthy people with a family history of diabetes had more knowledge about the risk factors for diabetes, and the significant variables in that study were ethnicity and a diet rich in energy. In a study by Baptiste-Roberts et al. [15], participants with a family history of diabetes had better knowledge of the risk factors for diabetes such as having a family member with diabetes, obesity, a high calorie diet, and a sedentary lifestyle.

Knowledge of complications of diabetes such as renal failure 
and sexual disorders were independent predictors of adherence to screening. This factor illustrates health literacy in the population analyzed in this study, although this factor was not evaluated in previous studies $[15,16,26,29,37]$. It seems that people were particularly concerned about vital organs (e.g., the kidneys) or sexual function. Thus, these complications of diabetes should be emphasized more in health education.

Participants who believed that urinalysis was the best method for screening had significantly lower adherence to screening. Testing levels of fasting blood glucose is a widely accepted means to diagnose diabetes [2]. Accordingly, assessing participants' knowledge of methods of diagnosing diabetes can be an indication of their general educational level and knowledge about diabetes. Similar studies did not assess this variable $[15,26,36]$.

Fast food consumption was another independent predictor of adherence to screening. In our study diabetes screening was inversely related to weekly fast food consumption. Although fast food consumption was not evaluated in similar studies $[15,16,26,27,29,36,37]$, this finding is related to the healthy person effect, according to which healthy people are more concerned about their health and participate more in screening programs.

Seventy-seven percent of the participants in this study had been screened for diabetes at least once and $43 \%$ had been tested in the past year. This finding is in line with that reported in the study of Nijhof et al. [26], in which $44 \%$ of participants had undergone a diabetes risk-screening test. In the latter study, participants' history of fasting blood glucose testing was not evaluated. Cowie et al. [21] found that 31\% of participants adhered to diabetes screening in the previous year. In a study by Hariri et al. [16], 69\% of participants with high familial risk for diabetes had been screened in the past 2 years. The difference among these findings may be due differences in the evaluation period.

The prevalence of obesity in this study was $19.2 \%$. Hariri et al. [16] found that the prevalence of obesity was $16.8 \%$, in their study evaluating both people with and without a family history of diabetes.

The effect of physical inactivity on developing diabetes is well understood [35]. About $62 \%$ of participants in this study were physically inactive, but this was not a predictor of screening adherence. This finding is in line with those of Morrison et al. [38] and Chang et al. [29], who showed that perceived risk for developing diabetes was not associated with healthy be- havior habits such as sufficient physical activity .

Approximately $6 \%$ of participants were current smokers. Smoking status was not a significant predictor of adherence to screening. Similar studies did not evaluate the effect of smoking on adherence to screening. In a study by Zlot et al. [27], smokers with a family history of diabetes reported quitting smoking for at least 1 day during the year before the study.

This survey was a descriptive study and causal conclusions cannot be drawn. It was not possible to detect possible cases of type 1 diabetes in the family members of participants, but this factor is likely to be negligible due to the low prevalence of type 1 diabetes among the general population [39]. Although we found that physicians' and healthcare providers' advice about the benefits of early disease detection was an independent predictor of screening adherence, we did not assess the actual number of healthcare providers who made these recommendations in their daily practice, which is an issue that requires further research. We also could not determine factors associated with low levels of knowledge and unwillingness to check fasting blood glucose in individuals with at least 1 family member with diabetes. To resolve this issue, in-depth interviews with diabetes patients and their first-degree family members are needed. We also used different analyses to control for the role of confounders and to evaluate interactions between the study variables. However, some doubts remain about the findings of the binary logistic regression model due to the limitations of stepwise regression, which may show some real explanatory variables with causal effects on the dependent variable as not statistically significant, while nuisance variables may be coincidentally significant.

A strength of this study is the fact that it was conducted at healthcare facilities because people attended these facilities for preventive services such as vaccination. However, this aspect may also be a confounding factor, as people who are more concerned about their health attend healthcare facilities; this is known as volunteer bias. All interviews were conducted by a single trained interviewer, which eliminated the possibility of variance between observers. This study was a cross-sectional study, so we could not assess the temporal relationship and causality between the study variables.

The findings of this study highlight the association between the advice of physicians and healthcare providers and adherence to screening among diabetes-free adults with a family history of diabetes. In light of the independent effect of gaining knowledge about diabetes from family on adherence to 
screening, it is worthwhile to inform people with diabetes that their first-degree family members have a higher risk of developing the disease. It should be emphasized to people with diabetes that preventing the onset of diabetes is possible, and that they should explain the advantages of early detection and control for their family members.

Primary healthcare centers could be used as a target for health education and increasing adherence to the screening of the at-risk population with a positive family history of diabetes. This could be used as advice in diabetes prevention protocols; specifically, when a healthcare provider finds a new case of diabetes, all the family members of at-risk age-groups should be invited for diabetes screening. We can assess such individuals based on the model defined in this study and adjust our personalized protocols to be more effective.

\section{SUPPLEMENTAL MATERIALS}

Supplemental material is available at https://doi.org/10. 3961/jpmph.20.496.

\section{CONFLICT OF INTEREST}

The authors have no conflicts of interest associated with the material presented in this paper.

\section{FUNDING}

None.

\section{ACKNOWLEDGEMENTS}

We would like to express our special thanks to the participants, healthcare providers at selected health centers, and the authorities of the sub-secretary for health of Shahid Beheshti University of Medical Sciences.

We wish to acknowledge the support of Research Department of the School of Medicine, Shahid Beheshti University of Medical Sciences for approval of this research. This paper was extracted from a thesis written by Dr. Narges Malih.

\section{AUTHOR CONTRIBUTIONS}

Conceptualization: NM. MRS. SA. AA. Data curation: NM. MRS. Formal analysis: NM. MRS. AA. Funding acquisition:
None. Methodology: NM. MRS. SA. AA. Project administration: NM. MRS. Writing - original draft: NM. MRS. SA. AA. Writing review \& editing: NM. MRS. SA. AA.

\section{ORCID}

Narges Malih https://orcid.org/0000-0002-5184-0881

Mohammad-Reza Sohrabi https://orcid.org/0000-00026811-3955

Alireza Abadi https://orcid.org/0000-0003-2653-6623

Shahnam Arshi https://orcid.org/0000-0003-0103-7596

\section{REFERENCES}

1. Guariguata L, Whiting DR, Hambleton I, Beagley J, Linnenkamp U, Shaw JE. Global estimates of diabetes prevalence for 2013 and projections for 2035. Diabetes Res Clin Pract 2014;103(2): 137-149.

2. World Health Organization. Global status report on noncommunicable diseases 2014 [cited 2020 Oct 1]. Available from: https://apps.who.int/iris/bitstream/handle/10665/148114/ 9789241564854_eng.pdf?sequence $=1$.

3. Azizi F, Hadaegh F. The increasing rate of diabetes and pre-diabetes in Iran. Iran J Endocrinol Metab 2015;17(1):1-3 (Persian).

4. Beagley J, Guariguata L, Weil C, Motala AA. Global estimates of undiagnosed diabetes in adults. Diabetes Res Clin Pract 2014; 103(2):150-160.

5. Najafipour M, Zareizadeh M, Najafipour F. Epidemiologic study of familial type 2 diabetes in Tehran. J Adv Pharm Technol Res 2018;9(2):56-60.

6. O Connor JM, Millar SR, Buckley CM, Kearney PM, Perry IJ. The prevalence and determinants of undiagnosed and diagnosed type 2 diabetes in middle-aged Irish adults. PLoS One 2013; 8(11):e80504.

7. Harrison TA, Hindorff LA, Kim H, Wines RC, Bowen DJ, McGrath $\mathrm{BB}$, et al. Family history of diabetes as a potential public health tool. Am J Prev Med 2003;24(2):152-159.

8. Annis AM, Caulder MS, Cook ML, Duquette D. Family history, diabetes, and other demographic and risk factors among participants of the National Health and Nutrition Examination Survey 1999-2002. Prev Chronic Dis 2005;2(2):A19.

9. Suchindran S, Vana AM, Shaffer RA, Alcaraz JE, McCarthy JJ. Racial differences in the interaction between family history and risk factors associated with diabetes in the National Health and Nutritional Examination Survey, 1999-2004. Genet Med 


\section{9;11(7):542-547.}

10. Mykkänen L, Laakso M, Uusitupa M, Pyörälä K. Prevalence of diabetes and impaired glucose tolerance in elderly subjects and their association with obesity and family history of diabetes. Diabetes Care 1990;13(11):1099-1105.

11. Lawrence JM, Bennett P, Young A, Robinson AM. Screening for diabetes in general practice: cross sectional population study. BMJ 2001;323(7312):548-551.

12. Tessaro I, Smith SL, Rye S. Knowledge and perceptions of diabetes in an Appalachian population. Prev Chronic Dis 2005; 2(2):A13.

13. Al-Sahouri A, Merrell J, Snelgrove S. Attitudes, knowledge, and perceptions of patients regarding type- 2 diabetes in Jordan. J Diabetes Mellit 2019;9:1-13.

14. Okosun IS, Davis-Smith M, Seale JP. Awareness of diabetes risks is associated with healthy lifestyle behavior in diabetes free American adults: evidence from a nationally representative sample. Prim Care Diabetes 2012;6(2):87-94.

15. Baptiste-Roberts K, Gary TL, Beckles GL, Gregg EW, Owens M, Porterfield D, et al. Family history of diabetes, awareness of risk factors, and health behaviors among African Americans. Am J Public Health 2007;97(5):907-912.

16. Hariri S, Yoon PW, Qureshi N, Valdez R, Scheuner MT, Khoury MJ. Family history of type 2 diabetes: a population-based screening tool for prevention? Genet Med 2006;8(2):102-108.

17. Ang BW, Tan MY, Goh CM, Rahardja S, Lim BY, Chiew W, et al. Impact of knowledge and attitudes on lifestyle practices in preventing type 2 diabetes mellitus. Ann Acad Med Singap 2019;48(8):247-263.

18. Konduru SS, Ranjan A, Karthik SM, Shaik S, Vakkapatla LS. Assessment of diabetes related knowledge, attitude and practice among diabetics and non-diabetics using self prepared questionnaire for awareness of health promotion. Indian J Pharm Pract 2017;10(1):33-38.

19. Tayefi B, Sohrabi MR, Kasaeian A. Patients' satisfaction with the diabetes control and prevention program in Tehran, Iran: a cross sectional study. J Res Health Sci 2015;15(4):239-243.

20. Aalavi Nia S, Ghotbi M, Mahdavi Hazaveh A, Kermanchi J, Nasli Isffahani AY. National diabetes type 2 prevention and contral program; 2012 [cited 2020 Oct 1]. Available from: https://www. gums.ac.ir/Upload/Modules/Contents/asset90/1500.pdf (Persian).

21. Cowie CC, Harris MI, Eberhardt MS. Frequency and determinants of screening for diabetes in the U.S. Diabetes Care 1994; 17(10):1158-1163.
22. American Diabetes Association. Standards of medical care in diabetes--2013. Diabetes Care 2013;36(Suppl 1):S11-S66.

23. Ajzen I. Constructing a theory of planned behavior questionnaire. Amherst: University of Massachusetts; 2006, p. 1-7.

24. Champion VL. Revised susceptibility, benefits, and barriers scale for mammography screening. Res Nurs Health 1999; 22(4):341-348.

25. Wilson SE, Rosella LC, Lipscombe LL, Manuel DG. The effectiveness and efficiency of diabetes screening in Ontario, Canada: a population-based cohort study. BMC Public Health 2010;10: 506.

26. Nijhof $\mathrm{N}$, ter Hoeven $\mathrm{CL}$, de Jong MD. Determinants of the use of a diabetes risk-screening test. J Community Health 2008; 33(5):313-317.

27. Zlot Al, Bland MP, Silvey K, Epstein B, Mielke B, Leman RF. Influence of family history of diabetes on health care provider practice and patient behavior among nondiabetic Oregonians. Prev Chronic Dis 2009;6(1):A27.

28. Teo $\mathrm{CH}, \mathrm{Ng} \mathrm{CJ}$, Booth $\mathrm{A}$, White A. Barriers and facilitators to health screening in men: a systematic review. Soc Sci Med 2016;165:168-176.

29. Chang MH, Valdez R, Ned RM, Liu T, Yang Q, Yesupriya A, et al. Influence of familial risk on diabetes risk-reducing behaviors among U.S. adults without diabetes. Diabetes Care 2011;34(11): 2393-2399.

30. Shah BR, Booth GL. Predictors and effectiveness of diabetes self-management education in clinical practice. Patient Educ Couns 2009;74(1):19-22.

31. Polubriaginof FC, Shang N, Hripcsak G, Tatonetti NP, Vawdrey DK. Low screening rates for diabetes mellitus among family members of affected relatives. AMIA Annu Symp Proc 2018; 2018:1471-1477.

32. De la Cruz AK, Tan CC, Cruz MD. Diabetes-related attitudes of health care providers in rural health centers in Aklan, Philippines using the Filipino version of Diabetes Attitude Scale (DAS-3). J ASEAN Fed Endocr Soc 2019;34(2):180-188.

33. Edelman D, Edwards LJ, Olsen MK, Dudley TK, Harris AC, Blackwell DK, et al. Screening for diabetes in an outpatient clinic population. J Gen Intern Med 2002;17(1):23-28.

34. Badlishah-Sham SF, Ramli AS, Isa MR, Mohd-Zaki N, Whitford DL. Are Malaysian type 2 diabetes patients willing to be trained to speak to their offspring about risk of diabetes and preventive measures? BMC Fam Pract 2020;21(1):50.

35. World Health Organization. Diabetes [cited 2020 Oct 1]. Available from: https://www.who.int/en/news-room/fact-sheets/ 
detail/diabetes.

36. Omolafe A, Mouttapa M, McMahan S, Tanjasri SP. We are family: family history of diabetes among African Americans and its association to perceived severity, knowledge of risk factors, and physical activity levels. Calif J Health Promot 2010;8(1): 88-97.

37. Hariri S, Yoon PW, Moonesinghe R, Valdez R, Khoury MJ. Evaluation of family history as a risk factor and screening tool for detecting undiagnosed diabetes in a nationally representative survey population. Genet Med 2006;8(12):752-759.

38. Morrison MK, Lowe JM, Collins CE. Perceived risk of type 2 diabetes in Australian women with a recent history of gestational diabetes mellitus. Diabet Med 2010;27(8):882-886.

39. Karvonen M, Viik-Kajander M, Moltchanova E, Libman I, LaPorte R, Tuomilehto J. Incidence of childhood type 1 diabetes worldwide. Diabetes Mondiale (DiaMond) Project Group. Diabetes Care 2000;23(10):1516-1526. 